\title{
Derechos fundamentales en el trabajo, poder y nuevas tecnologías*
} Fundamental Labor Rights, Power and New Technologies

\section{José Luis Ugarte Cataldo**}

\section{RESUMEN}

En el presente trabajo expondremos que la relación laboral es un espacio de poder que, como consecuencia de las nuevas tecnologías, se ha expandido crecientemente sobre los trabajadores. Por ello, plantea un relevante desafío para el derecho del trabajo, en particular respecto a cómo poner restricciones a ese poder privado. Analizaremos, asimismo, que ese tal desafio ha sido respondido en el contexto de la constitucionalización del derecho, a través de la idea de derechos fundamentales del trabajador, los cuales han sido considerados en una doble dimensión: como herramienta y como limite.

PALABRAS CLAVE: derechos fundamentales, poder empresarial, control, nuevas tecnologías, constitucionalización.

\begin{abstract}
In this paper we will present employment relationships as a space of power that as a consequence of the new technologies, these have expanded increasingly over workers. Therefore, it poses a relevant challenge for labor law, in particular regarding how to place restrictions on that private power. We will also analyze that this challenge has been answered in the context of the fundamental rights of the worker, which have been considered in a double dimension: as a tool and as a limit.
\end{abstract}

KEY WORDS: Fundamental Rights, Business power, Control, New technologies, Constitutionalization.

\footnotetext{
* Artículo de investigación. Recibido el 18 de octubre de 2018 y aceptado para su publicación el 17 de septiembre de 2019

**Profesor investigador en la Universidad Diego Portales, Chile. (jose.ugarte@udp.cl) orcid.org/0000-0002-0547-4534
} 


\section{SUMARIO}

1. Trabajo, poder y derechos: introducción

2. El trabajo como espacio de poder

3. La "constitucionalización" y el derecho del trabajo

4. Eficacia normativa de la Constitución

5. Los derechos fundamentales desde la perspectiva del trabajador

\section{Trabajo, poder y derechos: introducción}

De partida, ¿qué relevancia tiene la idea de “derechos fundamentales” para una vinculación contractual como la relación de trabajo? Esa relevancia se construye desde una premisa fundamental que hay que explicitar: el reconocimiento del carácter pluridimensional de la relación de trabajo. Esto es, una relación de carácter económico que sujeta al trabajador a las necesidades productivas de la empresa en una sociedad capitalista. Pero, al mismo tiempo, se constituye como una relación política, en el sentido de que estructura un poder privado en el contexto de una sociedad democrática.

Desde ese ángulo, se debe reconocer la doble dimensión del trabajador en las sociedades contemporáneas, como sujeto que forma parte de una relación laboral cuya finalidad es la productividad -y que se expresa en el vínculo contractual-, y como sujeto que forma parte de una relación de poder que lo expone a una subordinación fáctica y jurídica. De tal modo, esto es la justificación de la expansión de los derechos fundamentales en la relación de trabajo. ${ }^{1}$

En consecuencia, el reconocimiento de estos derechos para los trabajadores supone atender a toda la complejidad social del trabajo. Desde la doble dimensión señalada: la del trabajo como mercancía que se transa en un mercado- espacio de intercambio contractual-y la del trabajo como sujeción que somete al trabajador a un gobierno ajeno -espacio de poder privado-.

\footnotetext{
${ }^{1}$ En la concepción económica dominante, esa relación social de poder queda sutilmente oculta tras el velo del contrato y el trabajo como mercancía. Como sugiere Budd, ello sugiere que "las protege de ser cuestionadas". BudD, JoHN, El pensamiento sobre el trabajo, Valencia, Tirant Humanidades, 2014, p. 109).

En su celebres párrafos del fetichismo de la mercancia, Marx desvela el secreto: "Lo misterioso de la forma mercantil consiste, entonces, simplemente, en que esta refleja ante los hombres los caracteres sociales de su propio trabajo como caracteres materiales de los productos del trabajo, propiedades sociales naturales de dichas cosas; $y$, por tanto, en que también refleja la relación social de productores con respecto al trabajo total como una relación social de objetos, existentes fuera de ellos". Marx, Carlos, El Capital, tomo 1, libro I, Santiago, Lom, 2010, p. 83.
} 
Desde la perspectiva de la relación de trabajo, entendida como una relación jurídica de intercambio, lo que se exige al derecho es la protección del trabajador. Se trata de fijar aquellas bases que determinarán la forma en que la regulación legal deberá moverse, al momento de construir un modelo de legislación laboral tutelarmente conveniente. Este es el modo tradicional de mirar el derecho del trabajo y explica la justificación mínima de esa intervención sobre la relación laboral en todas las tradiciones jurídicas relevantes.

Debido a que la relación de trabajo es una relación de poder, pues pone a los trabajadores en una situación de sujeción y dominación respecto de otro particular, la finalidad exigible al sistema jurídico es doble. Por una parte, este debe fijar un espacio de inmunidad para el respeto de la dignidad del trabajador, con los derechos fundamentales como límite. Por otra parte, el sistema debe permitir la construcción de un "contrapoder" que opere como factor de equilibrio en la relación entre esas partes, teniendo los derechos fundamentales como herramienta.

En esta dimensión de la relación laboral, la idea de derechos fundamentales juega un doble rol: como límite y como herramienta. Para explicarlo, parece útil echar mano de la tradicional distinción en la doctrina laboral comparada respecto a esos derechos, en el ámbito del trabajo. Estos son los derechos de contenido propiamente laboral (específicos) y los derechos de contenido general (inespecíficos).

Los derechos de contenido laboral son una herramienta imprescindible para la construcción de un contrapoder que permita sostener el equilibrio entre la relación de trabajo y la represión del ejercicio arbitrario del poder empresarial. Así, ese tipo de derechos se vincula como lo que hemos denominado "libertad como no dominación" en el espacio de trabajo capitalista. ${ }^{2}$

En palabras de Rogmanoli, esta herramienta permite que los trabajadores logren "expropiar cuotas de autocracia privada", ${ }^{3}$ propia de la empresa moderna. Esta, a su vez, se refleja con nitidez en los poderes legales reconocidos al empleador y se manifiesta significativamente en la confección unilateral de las condiciones de trabajo.

Para sostener esa pretensión, la Constitución debe garantizar el espacio relevante a los sujetos que participan de la relación -la denominada autonomía colectiva-, así como las herramientas que faciliten a los trabajadores la construcción de una posición de poder de la que originalmente carecen: organizaciones colectivas (sindicatos) y mecanismos de presión (huelga).

\footnotetext{
${ }^{2}$ Véase Ugarte, José LuIs, Derecho del Trabajo: invención, teoría y crítica, Santiago, Thomson Reuters, 2015.

${ }^{3}$ Romagnol, Umberto, "El Derecho del Trabajo ante la crisis", Revista Derecho Social, núm. 58, p. 15.
} 
Por su parte, los derechos inespecíficos no buscan confrontar al poder empresarial, sino ponerle límites. Para ello, se reconocen espacios inmunes a ese poder, que protegen ciertos intereses individuales directamente vinculados a la dignidad moral del trabajador. Dicho en la terminología dominante, se refieren a los derechos asociados a la condición de ciudadano. A continuación, explicaremos con detalle esta distinción.

\section{El trabajo como espacio de poder}

En el trabajo, antes del derecho, está el poder. Exploremos, entonces, en qué consiste el poder que la empresa ejerce sobre el trabajador y que presión ejerce sobre sus derechos fundamentales.

De partida, en la literatura existe el consenso de que el poder es "un punto clave en el campo de las relaciones laborales" ya que "las relaciones laborales están centradas en los procesos de influencia y control sobre el trabajo". ${ }^{4}$ Por tanto, "debería ser evidente que la relación laboral es una forma específica de forma de poder" y que "el poder es una propiedad de la estructura, las actividades y los procesos característicos de las relaciones laborales y, como en todas las relaciones de poder, la lucha por el control es el rango central y constante". ${ }^{5}$

Las formas que adopta ese poder empresarial sobre el trabajador son múltiples. En primer lugar, se encuentra el poder organizacional, entendido como la administración y conducción del trabajo. La empresa tiene el poder para determinar los fines y los medios a través de los cuales se organizará la producción, sometiendo al trabajador a un sistema de producción que es ajeno. Como apunta Keenoy "la empresa es quien decide si habrá trabajo o no, y la gerencia quien disfruta el derecho a decidir cómo se va a organizar el trabajo". ${ }^{6}$

En segundo lugar, aparece el poder normativo, el cual consiste en la facultad de la empresa para fijar las normas internas que regulan cómo se trabaja. Estas determinan un orden disciplinario y establecen obligaciones, e incluso sanciones a los trabajadores disidentes. Este poder será ampliamente reconocido por los diversas culturales legales, que hablarán sin tapujos del poder disciplinario del empleador: "La empresa como institución, e incluso

\footnotetext{
${ }^{4}$ KIRKBRIDE, PAUL, "El poder", en Relaciones Laborales, La psicología de la influencia y el control en el trabajo, Madrid, Ministerio del Trabajo y Seguridad Social, 1994, p. 121.

${ }^{5}$ KeEnOY, Tom, "La creación de mecanismos de control", en Relaciones Laborales, La psicología de la influencia y el control en el trabajo, Madrid, Ministerio del Trabajo y Seguridad Social, 1994, p. 165.

${ }^{6}$ Keenor, Tom, "La creación de mecanismos de control", en Relaciones Laborales, La psicología de la influencia y el control en el trabajo, Madrid, Ministerio del Trabajo y Seguridad Social, 1994, p. 159.
} 
antes el empresario en la figura del patrón, ha ejercido tradicionalmente un intenso poder de dominio sobre sus propios subordinados, poder justificado en virtud de la obligación asumida por el trabajador dirigida no solo a realizar la concreta prestación sino también a respetar la disciplina laboral".?

Estas formas tradicionales de poder empresarial constituyeron lo que se denominaría el modelo de empresa taylorista, en referencia a la "organización científica del trabajo". ${ }^{8}$ El sentido de este modelo está marcado por la racionalización del trabajo, mediante un doble proceso: "un proceso de separación entre la concepción y el trabajo de ejecución; y un proceso de parcelación y repetitividad en los propios trabajos de concepción y de ejecución". ${ }^{9}$

Dicha forma de organización diseñada en torno a la idea de poder y control jerárquico exigirá la construcción de una "burocracia empresarial" dedicada a la vigilancia del cumplimiento obsesivo de los objetivos empresariales. ${ }^{10}$ Por ello, como apunta Keenoy: “A nivel de organización, la posición superior de la gerencia y al alcance del control administrativo están reforzados por la autoridad y la supervisión jerárquica convencionales y apoyados por unos reglamentos y procedimientos laborales". ${ }^{11}$

No es extraño que, con esa intensa forma de poder y las técnicas de control propias de las empresas fordistas en el capitalismo del siglo veinte, Foucault viera la concreción del viejo ideal benthamiano del "panóptico", expresado en la fábrica, la cárcel y el hospital:

\footnotetext{
7 Loy, GIAnNI, "El dominio ejercido sobre el trabajador", en El poder de dirección del empresario: nuevas perspectivas, Madrid, La Ley, 2005, p. 62.

${ }^{8}$ La obra de Frederick W. Taylor supuso una revolución en el capitalismo de entre guerras. Taylor, un ingeniero titulado por correspondencia, fue construyendo sus ideas a partir de su propia experiencia laboral: sirvió como obrero, jefe de cuadrilla, director y jefe de producción en la industria de acero (Midvale Steel Company). Su obra, presentada como una concepción científica sobre la organización del trabajo, tenía como filosofía subyacente la negación del conflicto capital-trabajo; el primero interesado en aumentar la producción, el segundo en aumentar los salarios. La sintesis del taylorismo es la división radical entre planificación - propia de la gerencia- y la ejecución del trabajo - propia de los obreros-. "El trabajo de cada obrero está completamente planificado por el management y cada obrero recibe, en la mayoría de los casos, instrucciones completas por escrito que describen en detalle la tarea que debe realizar, asi como los medios a utilizar para llevarla a cabo." TAYLOR, Frederick WinsLow, Management científico, Barcelona, Oikos-Tau, 2010, p. 55.

${ }^{9}$ Coriat, Benjamin, El taller y el cronometro, España, Siglo XXI, 2001, p. 107.

10 "En una perspectiva de mayor alcance histórico, el taylorismo puede interpretarse como la intersección en que coincide la máxima socialización del trabajo y su máxima subordinación al capital. Con su escrupulosa compartimentación de funciones y su principio vertical de la autoridad, contribuye a enlazar a un gran número de obreros en un gigantesco y único trabajador colectivo. La 'taylorización' del trabajo le otorga a la dirección de la empresa los medios para ejercer coacción tecnológica sobre los trabajadores." HopenhaYN, MaRTIN, Repensar el trabajo, Santiago, Editorial Norma, 2001, p. 154.

"KeEnOY, Tom, "La creación de mecanismos de control", en Relaciones Laborales, La psicología de la influencia y el control en el trabajo, Madrid, Ministerio del Trabajo y Seguridad Social, 1994, p. 159.
} 
En el panóptico se producirá algo totalmente diferente: ya no hay más indagación, sino vigilancia, examen. No se trata de reconstruir un acontecimiento, sino de vigilar sin interrupción y totalmente. Vigilancia permanente sobre los individuos por alguien que ejerce sobre ellos un poder -maestro de escuela, jefe de oficina, médico, siquiatra, director de prisión- y que, porque ejerce ese poder, tiene la posibilidad no solo de vigilar, sino también de constituir un saber sobre aquellos que vigila [ese] es un rasgo característico de nuestra sociedad: una forma de vigilancia que se ejerce sobre los individuos de manera individual y continua, como control y castigo y recompensa y como corrección, es decir como método de formación y transformación de los individuos en función de ciertas normas. ${ }^{12}$

Según el propio Foucault, el efecto más relevante del panóptico -incluida la fábrica- será la de inducir en el sujeto "un estado consciente y permanente de visibilidad que garantiza el funcionamiento automático del poder". ${ }^{13}$

En las últimas décadas, a esa forma tradicional de poder y control sobre los trabajadores, se han agregado nuevas formas de control, que lejos de aminorar la jerarquía empresarial, la han acrecentado exponencialmente. Y es que, como apunta con lucidez Crary, "la forma que toma la innovación dentro del capitalismo es la simulación continua de lo nuevo, mientras las relaciones de poder y control permanecen efectivamente iguales". ${ }^{14}$

¿En qué consisten estas nuevas tecnologías de poder empresarial? Por una parte, abarcan el control tecnológico-digital de la relación laboral, derivado del auge de las tecnologías de la información. Por otra parte, se encuentra el control emocional, reforzado por el ascenso de la "cultura de los valores empresariales". ${ }^{15}$

No es necesario extenderse con lo obvio: las tecnologías de la información permiten un control sobre los trabajadores inusualmente amplio. El empleador

\footnotetext{
${ }^{12}$ Focault, Michel, La verdad y las formas jurídicas, Barcelona, Gedisa, 2003, p. 125.

${ }^{13}$ Focault, Michel, Vigilar y castigar, Buenos Aires, Siglo XXI, 2004, p. 204.

${ }^{14}$ Crary, Jonathan, El capitalismo tardío y el fin del sueño (24/7), Buenos Aires, Paidós, 2015, p. 67.

${ }^{15}$ Como ha apunta sagazmente Warde, en esta nueva ideología empresarial, "como en los cultos, el adoctrinamiento permanente -seminarios de formación, retiros, sesiones plenarias- permite inocular los valores de la casa, destilar un discurso movilizador y aliviar el espíritu crítico. El credo de la empresa (su misión, sus objetivos) se recitan como un catecismo. Los himnos y las consignas - que abundan en metáforas deportivas y marciales- se entonan con entusiasmo. Hasta la ropa que se viste (frecuentemente ornada con el logo de la empresa), toda da prueba de la devoción del trabajador. En el gigante deportivo Nike, es de buen tono tatuarse en el tobillo el célebre logo. Algunas teorías de dudosa procedencia justifican las prácticas más extrañas. Con el pretexto de promover la cooperación y el espíritu de equipo, ejércitos de animadores, gestores y otros coaches enseñan a los asalariados 'el arte de ser uno mismo'. Como en los talk-shows (y como en los cultos), se les anima a confesar sus secretos más intimos". WARDE, IBRAHIM, "Estados Unidos y la religión del trabajo", en El Trabajo, Santiago, Le Monde Diplomatique, 2007, p. 47.
} 
puede mirar cualquier rincón de la empresa, pero también fuera de ella. Como explica Sennett: "Los nuevos sistemas de información proporcionan a los directivos un amplio cuadro de la organización y dejan a los individuos al margen de cuál sea su lugar en la red, poco espacio para esconderse [así, se suman] nuevas formas de poder desigual y arbitrario dentro de la organización". ${ }^{16}$

Pero no solo se trata del tradicional control vertical ahora potenciado por el uso de la informática, el ojo digital, sino también porque el trabajo ahora se hace a través -y cada vez más- de esa comunicación. Es decir, "en el posfordismo, cuando la línea de producción se convierte en flujo informativo, la gente trabaja precisamente comunicándose. La comunicación y el control se requieren mutuamente". ${ }^{17}$

De hecho, esta nueva capacidad tecnológica-informática al servicio del control produce un contradictorio incremento en la administración y control del trabajo, si se le pone en relación con el discurso de la cultura empresarial que publicita un supuesto aligeramiento de las estructuras empresariales. Como señala Sennett, el achatamiento de las antiguas jerarquías piramidales ha sido compatible con al aumento del control sobre los trabajadores:

Uno de los eslóganes de la nueva organización del trabajo es que descentraliza el poder, es decir que le otorga a la gente en los rangos más bajos de la organización el control sobre sus propias actividades [pero] esto no es así en la realidad, en función de las técnicas utilizadas para derribar a los viejos elefantes de la burocracia. Los nuevos sistemas de información proveen a los gerentes de primer nivel una imagen comprensiva de la organización de una forma que otorga a los individuos, en cualquier lugar de la red en que estén, poco lugar para esconderse. ${ }^{18}$

De ahí que la combinación de nuevas tecnologías y el gerencialismo ha incrementado excesivamente la presión administrativa sobre los trabajadores. Mientras, se espera que estos últimos sean sus propios auditores, sin que ello los libere de las atenciones de muchos auditores externos. No importa cuán provisorio sea, el trabajo ahora implica la realización de otros metatrabajos de confección de registros, el inventario de objetivos y metas, el compromiso con el llamado desarrollo profesional continuo. ${ }^{19}$

\footnotetext{
${ }^{16}$ Sennetr, Richard, La corrosión del carácter, Barcelona, Anagrama, 2010, p. 57.

${ }^{17}$ Fisher, MArk, Realismo capitalista, ¿no hay alternativa?, Buenos Aires, Editorial Caja Negra, 2016, p. 65.

${ }^{18}$ Fisher, Mark, Realismo capitalista ¿no hay alternativa?, Buenos Aires, Editorial Caja Negra, 2016, p. 73.

${ }^{19}$ Fisher, MARK, Realismo capitalista ¿no hay alternativa?, Buenos Aires, Editorial Caja Negra, 2016, p. 131.
} 
En relación con el control emocional que hoy se ejerce sobre los trabajadores, Berardi expone que, en los últimos tiempos, "el alma fue puesta a trabajar", lo cual constituiría "el núcleo esencial de la transformación posindustrial, de la transformación a la que estamos asistiendo en las últimas décadas del siglo $\mathrm{xx"}{ }^{20}$

Ese control "del alma" del trabajo se hace efectivo gracias a la difusión de una fuerte ideología en torno a la cultura de los valores de la empresa. ${ }^{21}$ En ese sentido, la cultura de los valores de la empresa se adiciona al control y vigilancia propia del taylorismo. Se trata de la pretensión empresarial por la adhesión del trabajador al proyecto e ideario simbólico de la empresa, a través de la difusión de agresivos programas de valores que buscan ese "control del alma", con la consiguiente pérdida de autonomía y libertad del personal. ${ }^{22}$

Como sugiere Willmot, los proyectos "humanizadores" de la cultura empresarial no reemplazan al viejo control jerárquico, sino que "superpone[n] un modo de control encaminado al potencial productivo presente en la naturaleza normativa y organizadora de la naturaleza humana”. La centralidad de ese control cultural es la autosupervisión. "Es de crucial importancia que el ámbito y orientación de la misma venga dictado y dirigido por la construcción del compartimiento del compromiso del empleado con los valores corporativos fundamentales.”23

En este nuevo taylorismo emocional -como lucidamente lo llama Hochschild-, "se obliga a introducir la relación social en canales estrictos: tal vez se conservan lugares ocultos en el margen, pero queda mucho menos espacio para

\footnotetext{
${ }^{20}$ Berardi, Franco, El trabajo del alma, Buenos Aires, Cruce, 2016, p. 135.

${ }^{21}$ Esa cultura de valores es acompañada de un proceso de control más blando vinculado con la "ideología de la felicidad". Como explica Berardi, "hacia fines de los setenta, la desafección obrera por el trabajo industrial, la crítica difusa de la jerarquía y la repetitividad habían quitado energía al capital. Todo el deseo estaba fuera del capital y atraía fuerzas que se alejaban de su dominio. Hoy sucede todo lo contrario: el deseo llama las energias hacia la empresa, hacia la autorrealización en el trabajo". Berardi "Bifo", Franco, La fábrica de infelicidad, Madrid, Traficantes de sueños, 2015, p. 59. Esa vinculación empresa y deseo de felicidad se expresará "a medida que los caracteres físico y psicológico del trabajo -y de la enfermedad - comienzan a confundirse entre sí, los conceptos de "salud", "felicidad" y "productividad" resultan todavía menos indistinguibles. Los patronos terminan por tratar las tres cosas como una sola entidad, a maximizar por medio de una serie de estimulos e instrumentos. Estamos hablando de la filosofía monista del directivo del siglo xxl: cada trabajador puede convertirse, o ser convertido, en uno mejor en los ámbitos del cuerpo, la mente y el rendimiento personal. DAVIES, WILLAM, La industria de la felicidad, Barcelona, Malpaso, 2015, p. 160.

${ }^{22}$ En ese sentido, Thompson y Ackroyd señalan que "el poder disciplinario constriñe a los individuos mediante el conocimiento de estos sobre sí mismos y su creencia en su propia soberanía como consumidor o empleado: el sujeto moderno reproduce voluntariamente las relaciones hegemónicas de dominación y explotación. El instrumento más habitual para llevar a cabo este sometimiento son los programas culturales de la empresa [y en ese sentido] la inseguridad del individuo, la cultura empresarial y el orden organizativo se constituyen unos a otros". THOMPSON, PAUL y AcKRoyd, StePHem, "¿Reina la calma en el frente de trabajo?: una crítica de las recientes tendencias en la sociología de trabajo en el Reino Unido", en Vigilar y Organizar, Una introducción a los Critical Magenement Studies, Madrid, Siglo XXI, 2007, p. 215.

${ }^{23}$ WiLmontr, Hugh, "La fuerza es la ignorancia, la esclavitud es la libertad: la gestión de la cultura de las organizaciones modernas", en Vigilar y Organizar, Una introducción a los Critical Magenement Studies, Madrid, Siglo XXI, 2007, p. 121.
} 
la navegación individual de las aguas emocionales”. ${ }^{24}$ De ahí, como apunta Frayne, "el sistema emocional privado ha pasado a estar regido por una lógica comercial, y el derecho del trabajador de dominar su propia conducta emocional y de interrelación ha sido eliminado". ${ }^{25}$

En ese sentido, el poder empresarial en la época contemporánea pretende acercarse a eso que Byung-Chul Han llama su nivel máximo, el poder libre: "El poder libre significa que el otro obedece libremente al yo. Quien quiera obtener un poder absoluto no tendrá que hacer uso de la violencia, sino de la libertad del otro. Ese poder absoluto se habrá alcanzado en el momento que libertad y sometimiento coincidan del todo". ${ }^{26}$

Existe también un "poder jurídico precarizador". Consiste en la ampliación de la gama de opciones que el derecho pone a disposición del empleador para relacionarse con el trabajo y sus titulares, los trabajadores. El empleador somete la conducta de los trabajadores con la posibilidad de ejercer sobre ellos formas jurídicas de flexibilidad interna (ius variandi, salarios de productividad, entre otros) y de precariedad externa (formas atípicas de contratación: subcontratación, suministro).

Esa gama de opciones jurídicas -incrementadas significativamente en el derecho laboral de las últimas décadas-genera una situación de disciplinamiento vía precariedad, cuyas consecuencias "desde el punto de vista del trabajador, son profundas: la organización colectiva y el alcance de las reclamaciones y los intereses es muchísimo más difícil para el personal temporal que ha sido contratado sobre una base de inseguridad". ${ }^{27}$

De ahí que Antunes apunte:

El escenario es aún más intenso en los estratos precarizados de la fuerza humana de trabajo, que experimentan las condiciones más carentes de derechos y viven en condiciones de inestabilidad cotidiana, dada por el trabajo part-time, temporario, precarizado [y que] bajo la incertidumbre y la superficialidad dadas por la condición de precarización o de riesgo de desempleo, la alienación puede asumir formas aún más intensificadas e incluso brutalizadas, pautadas por la pérdida [casi] completa de la dimensión de humanidad. ${ }^{28}$

\footnotetext{
${ }^{24}$ HochSCHILD, ARLE, The Managament Heart: Commercialisation of Human Feeling, Estados Unidos, University of California Press, 1983, p. 119.

${ }^{25}$ FraYNe, DaVID, El rechazo al trabajo, teoría y práctica de la resistencia al trabajo, Madrid, Akal, 2017, p. 65.

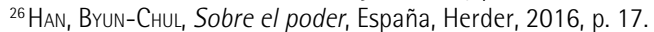

${ }^{27}$ Hartley, JeAn y Stephenson, Geoffrey, "La psicología de las relaciones laborales", en Relaciones laborales. La psicología de la influencia y el control en el trabajo, Madrid, Ministerio del Trabajo y Seguridad Social, 1994, p. 22.

${ }^{28}$ Antunes, RicARDo, "Marx y las formas actuales de alienación: cosificaciones inocentes y las cosificaciones extrañadas", en De regreso a Marx, Buenos Aires, Editorial Octubre, 2015, p. 227.
} 
El resultado de la combinación de poderes empresariales señalados y el contexto sociopolítico dominante no es un trabajador "liberado" del control y poder empresarial. Por el contrario, el resultado es "un incremento, tan notable como perturbador, de la intensificación del trabajo" en permanente búsqueda de la perfección, "y perfecto quiere decir estar siempre a disposición de la empresa. A cualquier hora del día. 0 de la noche". ${ }^{29}$ Así, se produce eso que acertadamente Fisher denomina el poder indefinido:

El trabajo sigue en casa, se trabaja desde la casa o se está como en casa en el lugar de trabajo, etc. Una consecuencia de este ejercicio "indefinido" del poder es que la vigilancia externa ya no es tan necesaria: en gran medida la sustituye la vigilancia interna. El Control solo funciona si uno es cómplice con él. De ahí viene esa figura de Burroughs, el "adicto al control” aquel que necesita fanáticamente controlar, pero que también es víctima él mismo del control que lo domina y lo posee. ${ }^{30}$

El resultado de todo este inédito y contemporáneo proceso de acumulación de poder en torno a la forma empresarial será la formación de eso que Anderson llama un "gobierno privado". Un gobierno privado, explica, es un "gobierno que tiene un poder arbitrario e incontrolable sobre los que gobierna". ${ }^{31}$

Volvamos al derecho en exacto punto. ¿Tiene algo que decir el derecho sobre este formidable proceso de acumulación de poder empresarial? ¿Como podría enfrentar el potente efecto desestabilizador que ese poder tiene en los intereses más relevantes del trabajador como ciudadano?

Pues bien, de partida, para que el derecho pueda erigir la idea de los derechos fundamentales como herramienta y límite frente a ese poder, se requerirá una profunda transformación constitucional. Dicha transformación se ha producido en el transcurso del siglo veinte y es conocida como constitucionalización del derecho del trabajo.

\footnotetext{
${ }^{29}$ CAstillo, Juan José, La invasión del trabajo en la vida, Madrid, Catarata, 2015, p. 68.

${ }^{30}$ Fisher, MARK, Realismo capitalista ¿no hay alternativa?, Buenos Aires, Editorial Caja Negra, 2016, p. 51.

${ }^{31}$ Anderson, Elizabeth, Private Government, How employers rule our lives, New Jersey, Princeton University Press, 2017, p. 45.
} 


\section{La "constitucionalización" y el derecho del trabajo}

En principio, cabe distinguir dos fenómenos jurídico-históricos que concurren bajo el mismo título. En efecto, podría sostenerse que la constitucionalización del derecho del trabajo ha operado en dos direcciones opuestas: la incorporación de normas laborales en la dimensión constitucional y su reverso, esto es, la irradiación de las normas de derechos fundamentales al orden laboral.

Así, se habla de constitucionalización del derecho del trabajo para el reconocimiento de derechos de carácter laboral, por las normas constitucionales de un determinado ordenamiento jurídico, proceso conocido como el "constitucionalismo social". Pero también existen para aquellos casos en que las normas constitucionales que estipulan derechos fundamentales de contenido general -no laborales- se proyectan en la regulación laboral, como efecto del carácter normativo de la Constitución.

Ambos procesos, así delineados, serán el soporte para que estos derechos pretendan cumplir su función frente al poder empresarial en el trabajo, como herramienta y como límite.

Revisemos estas dos caras de la moneda. En una primera dirección, el nombre de constitucionalización hará referencia a:

Las correcciones al liberalismo individualista que cristalizan constitucionalmente en dos importantes textos: la Constitución mexicana de Querétaro (1917) y la Constitución social-demócrata de la República de Weimar (1919); textos en los que emerge, como nuevo centro de imputación normativa, el trabajo humano y en los que se procede al reconocimiento de los derechos fundamentales, tanto individuales como colectivos, de los trabajadores. ${ }^{32}$

Se trata del constitucionalismo social y, en este sentido, significará dos cuestiones importantes: por una parte, una renovación del modelo antropológico de persona tras el texto constitucional -del propietario burgués al ciudadano

\footnotetext{
${ }^{32}$ Montoya, Alfredo, "El trabajo en la Constitución", en El trabajo y la Constitución, Estudios en homenaje al Profesor Alonso Olea, Madrid, Ministerio del Trabajo y Asuntos Sociales, 2003, p. 464. Aunque ambos textos constitucionales inauguran la dimensión social del orden constitucional, cabe señalar que sus alcances son diversos: en el caso mexicano hay una recepción social más limitada que el texto alemán, ya que se circunscribe fundamentalmente a la función social de la propiedad, especialmente la agrícola (artículo 27), y el reconocimiento de la protección del trabajo (artículo 123). La explicación parte de la relación con la fuerte influencia del movimiento obrero campesino en la Revolución de 1910, hecho político desencadenante del nuevo orden constitucional. En el caso alemán, la Constitución de Weimar tiene un sentido social amplio que abarcará cuestiones tan diversas como el derecho a la protección al trabajo (artículo 157), el derecho a la seguridad social (artículo 161), derecho a la sindicalización (artículo 159) vivienda digna (artículo 155) y a la instalación de consejos obreros para los trabajadores (artículo 147).
} 
en sentido amplio- ${ }^{33}$ y, por otra, una renovación con la igualdad material como objetivo constitucional relevante, mediante la estipulación de derechos con contenido social. Esta fase de constitucionalismo social:

Apareció de la mano de la crisis social de los años 30, y que puede ser considerada como la respuesta política-jurídica frente a un nuevo pico de radicalización social -una forma de evitar lo que ocurría en Europa a partir de la expansión de la ideología y demandas propias del socialismo. En tales textos tendieron a quedar consagrados los derechos del trabajador y sobre las condiciones laborales; protecciones en materia de seguridad social.

Esta nueva dirección del pensamiento jurídico "se corresponde con una modificación de la realidad social, con el desarrollo de la sociedad industrial, con la aparición progresiva de la clase trabajadora como nueva clase ascendente, con las condiciones económicas, sociales y culturales precarias en que vive, con las duras y penosas dimensiones en que desempeña su trabajo". ${ }^{34}$

Primeramente, se amplió el modelo antropológico del orden constitucional decimonónico. Este orden supone la "identificación exclusiva del hombre -titular universal de derechos- con el individuo, según la concepción ideológica del liberalismo, y del individuo con el burgués". ${ }^{35}$

La ampliación relatada abrió ese citado orden a una pluralidad de sujetos anteriormente ignorados (campesinos, asalariados, pobres, infantes, entre otros). Lo que importaría, la mayor parte de las veces, sería reconocer el derecho de organización de estos nuevos sujetos constitucionales, incluyendo, como caso paradigmático, las organizaciones sindicales.

El constitucionalismo decimonónico "presenta para el trabajador en relación de dependencia un déficit político considerable". ${ }^{36}$ Y ello se debe a su situación de "sirviente, doméstico, no propietario o no contribuyente en la

\footnotetext{
${ }^{33}$ En el Congreso Constituyente de Querétaro se dijo: "Así como Francia, después de su revolución, ha tenido el alto honor de consagrar en la primera de sus cartas magnas los inmortales derechos del hombre, así la Revolución mexicana tendrá el orgullo de mostrar al mundo que es la primera en consignar en una Constitución los sagrados derechos de los obreros". Véase Garcia Ramirez, Sergio, "Raiz y horizonte de los derechos sociales en la Constitución mexicana", Derechos Humanos, núm. 61, p. 85.

${ }^{34}$ PeCES-BARBA, Gregorio, "Los derechos económicos, sociales y culturales: su génesis y concepto", Derechos y libertades, núm. 6, p. 21.

${ }^{35}$ De LUCAS, JaVIER, El desafío de las fronteras. Derechos humanos y xenofobia frente a una sociedad plural, Madrid, Temas de hoy, 1994, p. 787.

${ }^{36}$ Vásouez Vialard, Antonio, "Fundamentos constitucionales del Derecho del Trabajo Argentino", en El trabajo y la Constitución, Estudios en homenaje al Profesor Alonso Olea, Madrid, Ministerio del Trabajo y Asuntos Sociales, 2003, p. 31.
} 
medida exigida por la ley constitucional o la ley ordinaria, con frecuencia no es elector, ni elegible". ${ }^{37}$

En segundo lugar, el constitucionalismo social revitalizaría los "compromisos igualitarios" que el liberalismo había logrado desterrar de los textos constitucionales en desmedro de la libertad. Ese liberalismo constitucional había sostenido un débil compromiso con la igualdad, que se restringía a la "igualdad legal", esto es, a la idea de que ella consistía en ser tratados todos por iguales en la ley. En consecuencia:

El cambio más significativo del tránsito del Estado de derecho al Estado social de derecho lo constituye la sustitución de una concepción formal por una material de igualdad; la realización de la igualdad ya no queda librada únicamente a las fuerzas del mercado, sino que depende de la continua y deliberada intervención de las autoridades públicas para promover personas, grupos y sectores desfavorecidos. ${ }^{38}$

Ese compromiso igualitario, ya reforzado constitucionalmente, se implementó a través de la recepción de los derechos sociales. Este proceso se aceleró en algunos aspectos del derecho occidental después del término de la Segunda Guerra Mundial, a través del reconocimiento explícito de tales derechos, los cuales: "ante la desigualdad en el punto de partida, pretenden la igualación en el punto de llegada para hacer posible una convivencia igual desde posiciones equiparables en la calidad de vida, en los medios de que disponen, en el ámbito de protección de que cada uno disfruta". ${ }^{39}$

Para esa pretendida igualación por los derechos sociales, es imprescindible abordar el problema del trabajo. De acuerdo con "ese modelo originario del derecho social, si el trabajo es el lugar central de integración social, las formas de redistribución de la riqueza deben ir vinculadas a la situación del trabajador asalariado". ${ }^{40}$

\footnotetext{
${ }^{37}$ Sagües, Nestor, "Constitucionalismo social", en Tratado de Derecho del Trabajo, Buenos Aires, Astrea, 1982, p. 671. La exclusión política y consiguientemente constitucional del trabajador en el siglo xIx vendrá a ser justificada desde la filosofía política liberal como un problema de libertad. "La repetición monótona y alienante de la misma tarea, la falta de educación, la ignorancia, impiden el desarrollo de verdaderos ciudadanos. Además, un pensamiento contraído se domina con mayor facilidad. Es lo que ocurre, precisamente, con la clase obrera, la gran damnificada en el proceso liberador que desata la sociedad comercial. Si la libertad es ausencia de dominación, el trabajador asalariado no es libre." Aguiar, Fernando, "¿Un Adam Smith republicano?, en Republicanismo y Democracia, Madrid, Editorial Mino y Davila, 2005, p. 115.

${ }^{38}$ Arango, Rodolfo, Derechos, constitucionalismo y democracia, Bogotá, U. Externado de Colombia, 2004, p. 68.

${ }^{39}$ Peces-Barba, Gregorio, "Reflexiones sobre los derechos sociales", en Derechos sociales y ponderación, Madrid, Fundación Coloquio Jurídico Europeo, 2007, p 92.

${ }^{40}$ Courtis, Christian, "Los derechos sociales en perspectiva", en Teoría del neoconstitucionalismo, Madrid, Trotta, 2007, p. 187.
} 
En busca de esa finalidad distributiva del nuevo orden constitucional, se erige como pieza fundamental el reconocimiento del derecho a la libertad sindical y los derechos vinculados al conflicto colectivo (negociación colectiva y huelga). ${ }^{41}$ En ese sentido, "el nacimiento y desarrollo del derecho social están marcados a fuego por el intento de codificar en términos jurídicos los conflictos relacionados con el trabajo asalariado". ${ }^{42}$

Desde entonces, estuvieron en el centro de ese constitucionalismo social los derechos fundamentales que operan como herramientas de poder para los trabajadores: la libertad sindical, la negociación colectiva y la huelga.

Expresado en términos de ciudadanía, dichos derechos fundamentales serán el soporte de una nueva dimensión de esta, que será designada como ciudadanía industrial por T. H. Marshall. ${ }^{43}$ Tal concepción de la ciudadanía industrial "se arraigó en las democracias liberales después de la Segunda Guerra Mundial” y corresponde a "un estado que limita la mercantilización de las personas en el empleo", encontrándose "inextricablemente ligada al crecimiento del estado de bienestar y los derechos sociales". ${ }^{4}$

Para los trabajadores, el sentido político de esas herramientas (sindicato, negociación y huelga) es evitar la total "mercantilización" del trabajo, mediante "la adquisición por los empleados de derechos dentro de la relación laboral, derechos que van más allá y están asegurados por fuerzas externas a la posición que los empleados pueden ganar puramente a través de las fuerzas del mercado laboral". ${ }^{45}$

Además, como dijimos, existe otro proceso de constitucionalización. La combinación de la denominada eficacia normativa de las normas constitucionales, particularmente de las que estipulan derechos fundamentales, con la eficacia horizontal de dichos derechos entre privados, especialmente en la relación

\footnotetext{
41 "El valor constitucional de la libertad tiene una cualificada expresión laboral, de dimensión tanto individual como colectiva, en la libertad sindical: un derecho reivindicado por el movimiento obrero desde sus orígenes. Reconocida en las Constituciones de Querétaro y Weimar y, a partir de ellas en todo el moderno constitucionalismo, la libertad sindical supone un avance trascendental a partir del simple derecho de asociación y reunión contemplado en las viejas constituciones del siglo xix." MontoYA, Alfredo, "El trabajo en la Constitución", en El trabajo y la Constitución, Estudios en homenaje al Profesor Alonso Olea, Madrid, Ministerio del Trabajo y Asuntos Sociales, 2003, p. 474.

${ }^{42}$ Courtis, Christian, Derechos sociales, ambientales y relaciones entre particulares, Bilbao, Cuadernos Deusto de Derechos Humanos, 2006, p. 15.

${ }^{43}$ Marshall, Thomas Humprey, Ciudadanía y clase social, Buenos Aires, Losada, 2005, p. 21. Como explica el sociólogo ingles esta forma de ciudadanía, que corre por fuera de la institucionalidad estatal -a diferencia de la ciudadanía civil, política y social - se encuentra fundada en la negociación colectiva llevada adelante por los gremios y que pudo desarrollarse al amparo de los derechos civiles contractuales -"mediante el uso del contrato en el mercado abierto"-.

${ }^{44}$ Fudge, Judy, "After Industrial Citizenship: Market Citizenship or Citizenship at Work?", Relations Industrielles / Industrial Relations, vol. 60, núm. 4, p. 632.

${ }^{45}$ Crouch, Counn, "The Globalized Economy: An End to the Age of Industrial Citizenship?", en Advancing Theory in Labor Law and Industrial Relations in a Global Context, Holanda, T. Wilthagen, 1998, p. 152.
} 
laboral, gatillarán un segundo cruce histórico entre el orden constitucional y el derecho del trabajo. Se hablará, entonces, de derechos fundamentales no laborales del trabajador y de ciudadanía en la empresa.

\section{Eficacia normativa de la Constitución}

La tradición jurídica continental del siglo XIX, incluida la latinoamericana, estaba construida como una "concepción predominantemente formalista y legalista de la Constitución, las cartas de derechos eran meras declaraciones de naturaleza política (y no jurídica) que requerirían, si habían de tener algún poder normativo directo, de desarrollo y configuración legal”. En ese escenario, los derechos fundamentales:

Calificaban, no como reglas, sino como principios [...] la aceptación de que los derechos eran principios (contenidos en meras "declaraciones”) implicaba que no tenían la fuerza normativa directa para ser litigados en sede judicial. Los verdaderos derechos eran tan solo posiciones directas y concretamente definidas en la ley sustantiva y procesal; los derechos constitucionales en cambio estaban lejos de definir directa y concretamente en qué ocasiones eran violados, en qué ocasiones se imponía su protección o qué remedios se imponían para su protección. ${ }^{46}$

En comparación, una idea extremadamente relevante del constitucionalismo de posguerra será considerar que las normas constitucionales tienen todas plena eficacia vinculante. Se incluyen también las que estipulan los derechos fundamentales de las personas y que, por tanto, son susceptibles de producir efectos jurídicos sin necesidad de desarrollo infra constitucional y, especialmente, sin necesidad de desarrollo legal. La Constitución "no es un catecismo político o una guía moral dirigida al legislador virtuoso, sino una norma como cualquiera otra que incorpora la pretensión de que la realidad se ajuste a lo que ella prescribe". ${ }^{47}$

En los textos constitucionales del derecho comparado se hará constar esa eficacia normativa de los derechos fundamentales. En el caso chileno, se reconoce, en efecto, bajo la denominación local de "principio de vinculación directa de la Constitución”. Esto según los claros términos de su artículo 6, inciso segundo,

\footnotetext{
${ }^{46}$ López Medina, Diego, Teoría impura del derecho, Bogotá, Legis, 2004, p. 446.

${ }^{47}$ Prieto Sanchis, Luis, Justicia constitucional y derechos fundamentales, Madrid, Trotta, 2009, p. 116.
} 
que señala: "Los preceptos de esta Constitución obligan tanto a los titulares o integrantes de dichos órganos como a toda persona, institución o grupo". Así, además, se desprende de modo inequívoco de los amplísimos términos en que está concebida la acción de amparo constitucional, que según el artículo 20 de la Constitución, puede ser ejercida en contra de "actos u omisiones arbitrarios o ilegales [que provoquen] privación, perturbación o amenaza en el legítimo ejercicio de los derechos y garantías" establecidas en el artículo 19, según los números que en dicho artículo se indican.

Algo parecido ocurre en el caso de diversas experiencias jurídicas en nuestro continente. En relación con el derecho peruano, se ha escrito que "aunque todos los preceptos constitucionales gozan de la misma fuerza normativa y, por tanto, de una capacidad de incidencia sobre el ordenamiento infra constitucional en principio equivalente, aquellos que se enmarcan dentro de la 'Constitución laboral' suelen desplegar una influencia sobre la configuración a nivel legislativo del ordenamiento laboral muy superior a la habitual". ${ }^{48}$

En relación con el derecho uruguayo, se ha escrito que la importancia de la Constitución "surge de su ubicación de primer rango en el sistema jerárquico, de forma tal que todo el orden normativo inferior se encuentra condicionado por sus preceptos, importancia que se ha visto acrecentada por el llamado proceso de constitucionalización del derecho laboral". ${ }^{49}$

Y, en el caso español, el artículo 9.1 y el artículo 53.1 de la Constitución española señalan respectivamente que: "los ciudadanos y los poderes públicos están sujetos a la Constitución y al resto del ordenamiento jurídico” y "los derechos y libertades reconocidos en el capítulo segundo del presente título vinculan a todos los poderes públicos”.

Por lo anterior, se afirma que, "en razón de lo dispuesto por estos artículos, es indiscutible que los derechos fundamentales son más que mera lírica constitucional". ${ }^{50}$ En ese sentido, la "consecuencia más básica consiste en concebir a los derechos como normas supremas, efectivas y directamente vinculantes, que pueden y deben ser observadas en toda operación de interpretación y aplicación del derecho". ${ }^{51}$

Sin embargo, falta una idea adicional en relación con las normas constitucionales: esa eficacia directa o normativa de la Constitución no solo se restringe a la regulación de las relaciones entre el Estado y los ciudadanos (eficacia

\footnotetext{
${ }^{48}$ Sanguineti, Wilfredo, Derecho Constitucional del Trabajo, Lima, Gaceta Juridica, 2007, p. 13.

${ }^{49}$ SERÉ, JoRgE, "Fuentes del Derecho del Trabajo", en Derecho del Trabajo, tomo 1, Montevideo, Fundación de Cultura Universitaria, 2012, p. 51.

${ }^{50}$ Bernal, Carlos, "Los derechos fundamentales y la teoría de los principios. ¿Es la teoría de los principios la base adecuada de los derechos fundamentales de la constitución española?", Doxa, núm. 30, p. 275.

${ }^{51}$ Prieto Sanchis, LuIs, "El constitucionalismo de los derechos", en Teoría del neoconstitucionalismo, Madrid, Trotta, 2007, p. 216.
} 
vertical), sino que también -y ahí la gran novedad- afecta las relaciones entre particulares (eficacia horizontal).

La idea central de esta transformación constitucional corresponderá a la eficacia horizontal de los derechos fundamentales, esto es, a "la posibilidad de que los particulares esgriman, en contra de otros particulares y en el ámbito de las relaciones privadas, los derechos subjetivos públicos como, por ejemplo, el derecho de propiedad, el derecho a no ser discriminado, la libertad de emitir opinión, el derecho a la intimidad o el derecho moral del autor". ${ }^{52}$

Esta es una novedad mayor para la tradición jurídica constitucional, pues "tradicionalmente se entendía que las normas constitucionales sobre derechos fundamentales se aplicaban únicamente a las relaciones entre los ciudadanos y el Estado; los derechos fundamentales habían aparecido históricamente como derechos de defensa frente a injerencias de los poderes públicos en la libertad de los particulares y, en consecuencia, no alcanzaban relaciones entre particulares". ${ }^{53}$

La idea de la eficacia horizontal supera esa forma reductiva de comprensión de los derechos fundamentales, y su éxito en el derecho comparado es significativo:

Con todo y con ello, no me parece arriesgado afirmar que la tesis de la eficacia horizontal de los derechos fundamentales se está, bajo una $\mathrm{u}$ otra forma, imponiendo en la mayor parte de los sistemas jurídicos [y que, salvo notables excepciones] ${ }^{54}$ cuenta no sólo con un consenso doctrinal muy amplio; constituye -y ello es más importante- una herramienta ampliamente utilizada en los ambientes jurídicos y judiciales comparados. ${ }^{55}$

Ese consenso se expresa, asimismo, en el derecho internacional. Tanto el Tribunal Europeo de Derechos Humanos, en aplicación de la Convención Europea de Derechos Humanos, ${ }^{56}$ como la Corte Interamericana de Derechos Humanos en aplicación de la Convención Americana sobre Derechos Humanos en Opinión

\footnotetext{
${ }^{52}$ PeÑa, Carlos, Sistema Juridico y Derechos Humanos, Santiago, U. Diego Portales, 1996, p. 668.

${ }^{53}$ FERRER I. RiBA, JosepH, Asociaciones, derechos fundamentales y autonomía privada, Madrid, Civitas, 1997, p. 89.

${ }^{54}$ En Estados Unidos pervive la idea de que los derechos fundamentales solo operan como protección frente a la acción de los poderes públicos, la llamada doctrina del state action. De ahi que se hable de "la impermeabilidad absoluta de la jurisprudencia norteamericana a la teoría de la Drittwirkung, incluso en su versión más suave". VALDÉs DAL-RE, Fernando, "Los derechos fundamentales de la persona del trabajador", Informe Congreso Mundial de Derecho del Trabajo, Montevideo, 2003, p. 81.

${ }^{55}$ ValdÉS DaL-RE, FeRnAndo, "Los derechos fundamentales de la persona del trabajador", Informe Congreso Mundial de Derecho del Trabajo, Montevideo, p. 69.

${ }^{56}$ El Tribunal Europeo de Derechos Humanos sostendrá que el Estado es responsable por la violación a la libertad sindical si tolera las prácticas empresariales que, con acuerdo de un sindicato, exigen a un trabajador elegir entre afiliarse a un sindicato o conservar el empleo, "Young, Jones \& Webster c Reino Unido", 13 de agosto de 1981, serie A, párrafos 54 a 56 .
} 
Consultiva, ${ }^{57}$ sostendrán abiertamente la doctrina del efecto horizontal de los derechos fundamentales.

En este último caso, la Corte Interamericana señala:

En una relación laboral regida por el derecho privado, se debe tener en cuenta que existe una obligación de respeto de los derechos humanos entre particulares. Esto es, de la obligación positiva de asegurar la efectividad de los derechos humanos protegidos, que existe en cabeza de los Estados, se derivan efectos en relación con terceros (erga omnes). Dicha obligación ha sido desarrollada por la doctrina jurídica y, particularmente, por la teoria drittwirkung, según la cual los derechos fundamentales deben ser respetados tanto por los poderes públicos como por los particulares en relación con otros particulares (Corte Interamericana de Derechos Humanos, Opinión Consultiva OC-18/03, párrafo 140).

Así, la relación laboral se muestra estructuralmente restrictiva con el ejercicio de derechos fundamentales del trabajador; no por razones éticas, como suele mostrar la metáfora del mal empleador -explotador-, sino, cosa distinta, por la racionalidad económica y tecnocrática sobre la cual se estructura el andamiaje de la producción de la empresa capitalista contemporánea.

Ante ese panorama, la irrupción de la eficacia directa e inmediata de los derechos fundamentales del trabajador en la relación laboral tiene una pretensión de efecto emancipador.

Desaparece, por obra de esa modernización que la Constitución impone, la configuración paternalista del poder empresarial como atributo de una responsabilidad personal frente a la comunidad; y como se elimina la sobrevaloración de los deberes de lealtad y fidelidad del trabajador

\footnotetext{
${ }^{57}$ La Corte Interamericana de Derechos Humanos sostendrá, en opinión solicitada por México, que los trabajadores inmigrantes -aún en condición de ilegales- tienen derecho al respeto y protección de sus derechos fundamentales, tanto respecto del Estado como de los particulares, Opinión Consultiva OC-18/03 "Condición jurídica y derechos de los migrantes indocumentados", 17 de septiembre de 2003. Esta Opinión Consultiva de la CIDH es -sin decirlo- una respuesta al fallo del Tribunal Supremo de los Estados Unidos "Hoffman Plastic Compounds v. National Labor Relations Board" (2002), que había negado el derecho de un inmigrante mexicano para cobrar salarios por un despido en represalia por el ejercicio de los derechos sindicales establecidos en la National Labor Relations Act. Como apunta Mijangos y González: "El Tribunal Supremo sostuvo que la prohibición de trabajar sin autorización, prevista en la ley de inmigración, prevalecia sobre el derecho de formar y ser parte de un sindicato". MIJANGOS y GonZÁLEZ, JAVIER, Los derechos fundamentales entre particulares, México, Porrúa, 2007, p. 195.
} 
a la empresa como expresión de una subordinación personal a un modélico funcionamiento de la producción. ${ }^{58}$

Por lo anterior, se trata de que la "empresa se convierta en parte de una república y los trabajadores conservan siempre sus derechos, incluso dentro de la empresa". ${ }^{59}$ Este cambio de mirada sobre la Constitución, y particularmente sobre los derechos constitucionales, tendrá profundos efectos en el derecho del trabajo, como veremos en adelante.

\section{Los derechos fundamentales desde la perspectiva del trabajador}

Los procesos de expansión y transformación constitucional recién delineados situaron en el centro de las relaciones laborales los derechos fundamentales, como una técnica de protección. Por tratarse de dos fases de constitucionalización diferentes se estableció en la doctrina laboral una distinción respecto de estos derechos: para el caso del constitucionalismo social se ha hablado de derechos fundamentales específicos y, para el caso de la ciudadanía en la empresa, se ha hablado de los derechos fundamentales inespecíficos.

Por una parte, circundan en torno al sujeto "los derechos específicamente laborales de que son titulares los trabajadores asalariados o empleadores en tanto que sujetos de una relación laboral" (paradigmáticamente, derecho a la huelga y negociación colectiva). Por otra parte, se encuentran "los derechos constitucionales de carácter general y, por ello, no específicamente laborales que pueden ser ejercidos, sin embargo, por sujetos de las relaciones de trabajo -los trabajadores en particular- en el ámbito de las mismas, por lo que en tal caso adquieren un contenido o dimensión laboral sobrevenidos". ${ }^{60}$

Aunque pareciera lo mismo, pues estamos hablando de derechos fundamentales cuyo titular es el trabajador, cabe destacar relevantes diferencias entre ambas fases de la constitucionalización del derecho del trabajo. La diferencia central entre ambos procesos de expansión constitucional se atribuye a su función política y económica. Es ahí donde se explica la diferencia entre el límite y la herramienta.

\footnotetext{
${ }^{58}$ González Ortega, Santiago, "La aplicación judicial difusa de la Constitución en el orden jurisdiccional social", Cuadernos de Derecho Público, núm. 7, p. 211.

${ }^{59}$ GheZZI, Giorgio y Romagnol, Umberto, II rapporto di lavoro, Bologna, Zanichelli, 1987, p. 26.

${ }^{60}$ Palomeque, Manuel Carlos, "Derechos fundamentales generales y relación laboral: los derechos laborales inespecíficos", en El modelo social de la Constitución española de 1978, Madrid, Ministerio del Trabajo y Asuntos Sociales, 2003, p. 229.
} 
Los derechos constitucionales generales (inespecíficos) no buscan deslizar parte del poder en disputa en la relación laboral hacia el lado de sus titulares, los trabajadores, sino garantizar un espacio de inmunidad que fije la frontera donde ese poder se detiene.

En cambio, los derechos fundamentales laborales, en su versión colectiva, encuentran su mejor sentido en la constitución de un "contra-poder". Estos buscan que sea posible oponerse a la sujeción que el capital establece sobre el trabajo, con el fin de reestablecer la libertad en ese espacio. "La invención de la dimensión colectiva ha permitido salir del dilema de la subordinación voluntaria, restituyendo al trabajador su cualidad de sujeto libre, sin cuestionar su subordinación: se le da en el plano colectivo la autonomía de que se le priva en el plano individual." ${ }^{61}$

Desde el derecho, ¿qué puede explicar la menor ofensividad política de unos en relación con los otros? La respuesta implica la relación con el titular y la pretensión protegida.

Los derechos fundamentales generales inespecíficos exhiben una titularidad de carácter individual, que suele estar al servicio de una posición de defensa, cuyo correlato, por regla general, es un deber negativo para el poder empresarial. Ese deber negativo - un no hacer- puede ser traducido en una sola prohibición general que constituye el límite del cual venimos hablando: no invadir el espacio protegido por el derecho fundamental de que se trata.

Por su parte, los derechos fundamentales laborales, particularmente la negociación colectiva y la huelga, o son derechos de carácter colectivo o individuales, pero de ejercicio colectivo. Su contenido protegido es una autonomía organizativa y funcional, con el fin de que sean sus titulares los que decidan cuáles acciones serán las necesarias para contrarrestar el poder empresarial. No se busca solo la distribución de utilidades económicas entre las partes, sino del poder mismo al interior de la relación laboral. ${ }^{62}$ Son herramientas al servicio de sus titulares para que ellos decidan qué hacer con estas.

De este modo, esos derechos fundamentales han sido entendidos como herramientas en diversas tradiciones jurídicas comparadas. De ellos se ha dicho que:

\footnotetext{
${ }^{61}$ Supiot, Alain, Critica del Derecho del Trabajo, Madrid, Ministerio del Trabajo y Asunto Sociales, 1996, p. 164.

${ }^{62} \mathrm{Se}$ habla, así, de "un derecho de doble titularidad, siendo las representaciones colectivas titulares directas de unos contenidos del derecho, mientras que corresponden otras facetas de este a los individuos representados por formaciones colectivas". Rivero, JuAn y De Val Tena, Ángel LuIS, "El derecho a la negociación colectiva: reconocimiento constitucional y garantías legales", en Modelo social en la Constitución española de 1978, Madrid, Ministerio del Trabajo y Asuntos Sociales, 2003, p. 655. En la misma línea, respecto de la huelga, Ray señala: "Es un derecho que pertenece a cada asalariado, único titular de este derecho constitucional. Pero si el asalariado hace la huelga él solo, en principio, incurre en culpa porque la huelga tiene que ser ejercida colectivamente". Ray, Jean-Emmanuel, La huelga hoy en el derecho social comparado, Madrid, Esade, 2007, p. 233.
} 
Entre otras significaciones tienen la de legitimar medios de defensa a los intereses de grupos y estratos de la población socialmente dependientes [y que en el caso de la huelga operan] como instrumento de presión constitucionalmente reconocido, que la experiencia secular ha mostrado ser necesario para la afirmación de los intereses de los trabajadores en conflictos socioeconómicos, conflictos que el Estado social no puede excluir, pero a los que sí puede y debe proporcionar los adecuados cauces institucionales.

En el mismo sentido, se dirá en la jurisprudencia constitucional alemana que:

El derecho fundamental protege, además - como actividad sindical-, las medidas de protesta laboral orientadas a la celebración de contratos colectivos. De acuerdo con esto, son comprendidas, en todo caso, dentro de la libertad de asociación sindical, en la medida que se requieran para asegurar la funcionalidad de la autonomía en las negociaciones sindicales (véase BVerfGE 84, 212 [224 y ss.]). Dentro de éstas se encuentra también el derecho de huelga (véase BVerfGE 88, 103 [114]). La autonomía del contrato colectivo es funcionalmente capaz sólo en la medida que entre las partes del contrato colectivo exista un equilibrio de fuerza -paridad- (véase BVerfGE 84, 212 [229]). Una reglamentación es incompatible en todo caso con el artículo 9, párrafo 3 de la Ley Fundamental, cuando lleva a que no se garantice más en caso de controversia, la capacidad negocial de las partes en un contrato colectivo, incluyendo la capacidad para llevar a cabo una lucha laboral efectiva, y se restrinja adicionalmente la actividad sindical que se requiere para equilibrar los derechos fundamentales de ambas partes.

En el caso chileno la cuestión no será distinta, pues, en relación con este tipo de derechos:

Se presenta como el rechazo por parte del factor trabajo, de manera concertada y colectiva, a continuar realizando su aporte, con miras a lograr mejoras en sus condiciones y su situación social, cuando desestimadas por el capital. En este sentido se hace manifiesto su carácter de presión ante el empleador; es un "ultimátum" a la patronal, que se enfrenta a la inminencia de la suspensión de labores y consecuente paralización del proceso productivo. Carecen los dependientes de otra herramienta pacífica que pueda contrapesar la autonomía y poder de la 
propiedad. Su necesidad está intima y directamente unida a la reivindicación de derechos que se consideran conculcados e, indirectamente, al bien común.

Además, se trata de derechos con una intensa connotación político-distributiva, que se enmarcan en la ciudadanía en la empresa, entendida como:

Recuperación de aspectos económicos y sociales de la misma -es decir a través de la consecución de la igualdad sustancial, no formal- que solo podía realizarse a través de los colectivos, de la acción de las organizaciones representativas de los trabajadores. El constitucionalismo industrial tiene ese sesgo, la generación de instituciones de contrapoder colectivo. Este es el principio fundante de la democracia industrial, de la democracia colectiva. ${ }^{63}$

En ese sentido, dichos derechos son expresión de la institucionalización del conflicto central de las sociedades capitalistas modernas, como lo es la disputa salarial del reparto de las utilidades sociales agregadas entre los factores del trabajo. De ahí que dicho conflicto aparezca "regulado por un potente aparato normativo, y que da lugar a formas relativamente ordenadas de protesta, enmarcadas en un contexto que tiene como principal referente la negociación colectiva". ${ }^{64}$

Es evidente la fuerte connotación política que los derechos fundamentales específicos tienen para un sistema de relaciones laborales. Por ello, no es de extrañar que, tal como lo señala ampliamente la doctrina, con la introducción en el texto constitucional de la libertad sindical, la negociación colectiva y la huelga tendrán una clara consecuencia político-institucional: la pretensión de un sistema democrático de relaciones laborales. ${ }^{65}$

La naturaleza de los derechos fundamentales inespecíficos del trabajador, en cambio, es diversa. Se trata preponderantemente de derechos de titularidad individual cuyo contenido es la protección de un espacio de inmunidad frente a

\footnotetext{
${ }^{63}$ Baylos, Antonio, Derecho del Trabajo: un modelo para armar, Madrid, Trotta, 1997, p. 96.

${ }^{64}$ Alonso, Luis Enrioue, Trabajo y ciudadanía: Estudios sobre la crisis de la sociedad salarial, Madrid, Trotta, 1999, p. 50.

${ }^{65}$ En efecto, se afirmará que el reconocimiento constitucional de la libertad sindical y de la huelga es una consecuencia precisa de una toma de posición de política jurídica asumida por el legislador constituyente, referida a "la cláusula de Estado social y democrático de derecho (artículo 1.1 CE) que, entre otras significaciones, tiene la de legitimar medios de defensa a los intereses de los grupos y estratos de la población socialmente dependientes, y entre los cuales se cuenta el de "otorgar reconocimiento constitucional a un instrumento de presión que la experiencia secular ha mostrado ser necesario para la afirmación de intereses de los trabajadores en conflictos socioeconómicos". Palomeque, Manuel Carlos, "El derecho constitucional de huelga y su regulación en España", en Derecho del Trabajo y razón crítica. Libro dedicado al Profesor Manuel Carlos Palomeque, Salamanca, 2004, p. 138.
} 
terceros. En ese sentido corresponden, técnicamente, a los denominados clásicos derechos de defensa. Es decir, son derechos que "ponen límites al Estado para asegurar espacios individuales de libertad, en consonancia con la concepción liberal clásica de los derechos fundamentales". ${ }^{66}$

Pero, donde se encuentra la diferencia más relevante y que se liga con lo anteriormente apuntado es en las consecuencias políticas de ambos procesos. Mientras los derechos fundamentales específicos (como la negociación colectiva y la huelga) están encaminados a producir un significativo efecto de reparto del poder empresarial -en atención a su pretensión de reequilibrar las relaciones laborales-, el ejercicio de los derechos fundamentales inespecíficos exhibe un sentido político más modesto: asegurar un espacio de autonomía personal para el trabajador.

Dicho de otro modo, los derechos fundamentales no laborales o inespecíficos buscan limitar el poder empresarial, a favor de la libertad y la autonomía personal. Mientras, los derechos fundamentales propiamente laborales o específicos buscan repartir ese mismo poder, en razón de la igualdad o de la propia libertad.

Insistimos en que unos operan como límites; los otros, como herramientas. Pero esas relevantes diferencias no deben opacar aquello que los une. Ambos tipos de derechos fijan un nexo del trabajo con la ciudadanía, si es que entendemos esa condición en sentido amplio: "como un estado que limita la mercantilización" y confiere a los trabajadores "derechos para influir en las condiciones de trabajo". ${ }^{67}$

De ese modo, pese al diverso papel que cada tipo de derecho tiene en la tarea de construir un derecho del trabajo robusto, radicalmente ligado al contrapoder de los trabajadores, ${ }^{68}$ es necesario reconocer el íntimo nexo de los derechos fundamentales en cualquiera de sus versiones con la idea que desvincula al trabajador de su condición de mercancía: la de ciudadanía. Esta condición, en fin, expresa "el logro de derechos que los trabajadores poseen por razón de formar parte de una comunidad humana y que son conferidos por fuerzas institucionales, más que por fuerzas de mercado". ${ }^{9}$

\footnotetext{
${ }^{66}$ Arango, Rodolfo, El concepto de derechos sociales fundamentales, Bogotá, Legis, 2005, p. 35.

${ }^{67}$ Barbalet, Jack, Citizenship: Rights, Struggle and Class Inequality, Publisher, Open University Press, 1988, p. 26.

${ }^{68}$ Véase UGARTE, José LuIs, Derecho del Trabajo: invención, teoría y crítica, Santiago, Thomson Reuters, 2015, pp. 93-127.

${ }^{69}$ Budd, John, El pensamiento sobre el trabajo, Valencia, Tirant Humanidades, 2014, p. 122.
} 


\section{Referencias}

Aguiar, Fernando, “¿Un Adam Smith republicano?, en Republicanismo y Democracia, Madrid, Editorial Mino y Davila, 2005.

Alonso, Luis Enrique, Trabajo y ciudadania: Estudios sobre la crisis de la sociedad salarial, Madrid, Trotta, 1999.

Anderson, Elizabeth, Private Government, How employers rule our lives, New Jersey, Princeton University Press, 2017.

Antunes, Ricardo, "Marx y las formas actuales de alienación: cosificaciones inocentes y las cosificaciones extrañadas”, en De regreso a Marx, Buenos Aires, Editorial Octubre, 2015.

Arango, Rodolfo, Derechos, constitucionalismo y democracia, Bogotá, U. Externado de Colombia, 2004.

Arango, Rodolfo, El concepto de derechos sociales fundamentales, Bogotá, Legis, 2005. Barbalet, Jack, Citizenship: Rights, Struggle and Class Inequality, Publisher, Open University Press, 1988.

Baylos, Antonio, Derecho del Trabajo: un modelo para armar, Madrid, Trotta, 1997. Berardi, Franco, La fábrica de infelicidad, Madrid, Traficantes de sueños, 2015.

Berardi, Franco, El trabajo del alma, Buenos Aires, Cruce, 2016.

Bernal, Carlos, "Los derechos fundamentales y la teoría de los principios. ¿Es la teoría de los principios la base adecuada de los derechos fundamentales de la constitución española?", Doxa, núm. 30.

Budd, John, El pensamiento sobre el trabajo, Valencia, Tirant Humanidades, 2014.

Castillo, Juan José, La invasión del trabajo en la vida, Madrid, Catarata, 2015.

Coriat, Benjamin, El taller y el cronometro, España, Siglo XXI, 2001.

Courtis, Christian, Derechos sociales, ambientales y relaciones entre particulares, Bilbao, Cuadernos Deusto de Derechos Humanos, 2006.

Crary, Jonathan, El capitalismo tardío y el fin del sueño (24/7), Buenos Aires, Paidós, 2015.

Своuch, Colin, "The Globalized Economy: An End to the Age of Industrial Citizenship?", en Advancing Theory in Labor Law and Industrial Relations in a Global Context, Holanda, T. Wilthagen, 1998.

104 Davies, William, La industria de la felicidad, Barcelona, Malpaso, 2015.

De LuCAS, JAVIER, El desafío de las fronteras. Derechos humanos y xenofobia frente a una sociedad plural, Madrid, Temas de hoy, 1994.

FERRER I. RibA, JoSEPH, Asociaciones, derechos fundamentales y autonomía privada, Madrid, Civitas, 1997.

FisHeR, MARK, Realismo capitalista ¿no hay alternativa?, Buenos Aires, Editorial Caja Negra, 2016.

Focault, Michel, La verdad y las formas jurídicas, Barcelona, Gedisa, 2003.

Focault, Michel, Vigilar y castigar, Buenos Aires, Siglo XXI, 2004. 
FRAYNE, DAVID, El rechazo al trabajo, teoría y práctica de la resistencia al trabajo, Madrid, Akal, 2017.

Fudge, Judy, “After Industrial Citizenship: Market Citizenship or Citizenship at Work?”, Relations Industrielles / Industrial Relations, vol. 60, núm. 4.

García Ramírez, Sergio, "Raíz y horizonte de los derechos sociales en la Constitución mexicana”, Derechos Humanos, núm. 61.

Ghezzi, Giorgio y Romagnoli, Umberto, Il rapporto di lavoro, Bologna, Zanichelli, 1987. Han, Byun-Chul, Sobre el poder, España, Herder, 2016.

Hartley, Jean y Stephenson, Geoffrey, "La psicología de las relaciones laborales", en

Relaciones laborales. La psicología de la influencia y el control en el trabajo, Madrid, Ministerio del Trabajo y Seguridad Social, 1994.

Hochschild, Arlie, The Managament Heart: Commercialisation of Human Feeling, Estados Unidos, University of California Press, 1983.

Hopenhayn, Martin, Repensar el trabajo, Santiago, Editorial Norma, 2001.

KeEnoy, Tom, "La creación de mecanismos de control", en Relaciones Laborales, La psicología de la influencia y el control en el trabajo, Madrid, Ministerio del Trabajo y Seguridad Social, 1994.

KirkBride, PAUL, "El poder", en Relaciones Laborales, La psicología de la influencia y el control en el trabajo, Madrid, Ministerio del Trabajo y Seguridad Social.

López Medina, Diego, Teoría impura del derecho, Bogotá, Legis, 2004.

Loy, GiAnNi, "El dominio ejercido sobre el trabajador", en El poder de dirección del empresario: nuevas perspectivas, Madrid, La Ley, 2005.

Marshall, Thomas Humprey, Ciudadania y clase social, Buenos Aires, Losada, 2005.

MarX, Carlos, El Capital, tomo 1, libro I, Santiago, lom, 2010.

Mijangos y GonzÁlez, JAVIER, Los derechos fundamentales entre particulares, México, Porrúa, 2007.

Montoya, Alfredo, "El trabajo en la Constitución”, en El trabajo y la Constitución, Estudios en homenaje al Profesor Alonso Olea, Madrid, Ministerio del Trabajo y Asuntos Sociales, 2003.

Palomeque, Manuel Carlos, "Derechos fundamentales generales y relación laboral: los derechos laborales inespecíficos”, en El modelo social de la Constitución española de 1978, Madrid, Ministerio del Trabajo y Asuntos Sociales, 2003.

Palomeque, Manuel Carlos, "El derecho constitucional de huelga y su regulación en

España”, en Derecho del Trabajo y razón critica. Libro dedicado al Profesor Manuel Carlos Palomeque, Salamanca, 2004.

Peces-Barba, Gregorio, "Los derechos económicos, sociales y culturales: su génesis y concepto”, Derechos y libertades, núm. 6.

Peces-Barba, Gregorio, "Reflexiones sobre los derechos sociales", en Derechos sociales y ponderación, Madrid, Fundación Coloquio Jurídico Europeo, 2007.

Peña, Carlos, Sistema jurídico y derechos humanos, Santiago, U. Diego Portales, 1996. 
Prieto Sanchis, Luis, "El constitucionalismo de los derechos", en Teoría del neoconstitucionalismo, Carbonell (ed.), Madrid, Trotta, 2007.

Prieto Sanchis, Luis, Justicia constitucional y derechos fundamentales, Madrid, Trotta, 2009.

Ray, Jean-Emmanuel, La huelga hoy en el derecho social comparado, Madrid, Esade, 2007. Rivero, Juan y De Val Tena, Ángel Luis, "El derecho a la negociación colectiva: reconocimiento constitucional y garantías legales", en Modelo social en la Constitución española de 1978, Madrid, Ministerio del Trabajo y Asuntos Sociales, 2003.

Romagnoli, Umberto, "El Derecho del Trabajo ante la crisis", Revista Derecho Social, núm. 58.

Sagües, Nestor, "Constitucionalismo social”, en Tratado de Derecho del Trabajo, Vásquez (coord.), Buenos Aires, Astrea, 1982.

Sanguineti, Wilfredo, Derecho Constitucional del Trabajo, Lima, Gaceta Jurídica, 2007. Sennetr, Richard, La corrosión del carácter, Barcelona, Anagrama, 2010.

Seré, Jorge, "Fuentes del Derecho del Trabajo", en Derecho del Trabajo, tomo 1, Montevideo, Fundación de Cultura Universitaria, 2012.

Supiot, Alain, Critica del Derecho del Trabajo, Madrid, Madrid, Ministerio del Trabajo y Asuntos Sociales, 1996.

Loy, Gianni, "El dominio ejercido sobre el trabajador", en El poder de dirección del empresario: nuevas perspectivas, Madrid, La Ley, 2005.

Thompson, Paul y Ackroyd, Stephem, “¿Reina la calma en el frente de trabajo?: una crítica de las recientes tendencias en la sociología de trabajo en el Reino Unido", en Vigilar y Organizar, Una introducción a los Critical Magenement Studies, Madrid, Siglo XXI, 2007.

UgarTe, José LuIs, Derecho del Trabajo: invención, teoría y crítica, Santiago, Thomson Reuters, 2015.

VAldÉs Dal-Re, Fernando, "Los derechos fundamentales de la persona del trabajador", Informe Congreso Mundial de Derecho del Trabajo, Montevideo, 2003.

VÁsquez Vialard, Antonio, "Fundamentos constitucionales del Derecho del Trabajo Argentino", en El trabajo y la Constitución, Estudios en homenaje al Profesor Alonso Olea, Madrid, Ministerio del Trabajo y Asuntos Sociales, 2003.

Warde, Ibrahim, “Estados Unidos y la religión del trabajo”, en El Trabajo, Santiago, $106 \quad$ Le Monde Diplomatique, 2007.

Willmontt, Hugh, "La fuerza es la ignorancia, la esclavitud es la libertad: la gestión de la cultura de las organizaciones modernas", en Vigilar y Organizar, Una introducción a los Critical Magenement Studies, Madrid, Siglo XXI, 2007. 